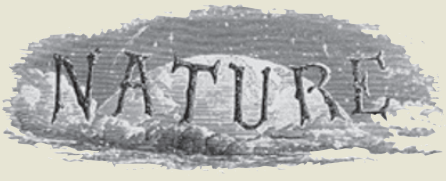

\section{Years Ago}

The Television Research Committee was appointed by the Home Secretary in July 1963, to initiate and co-ordinate research into the part which television plays, or could play, as a medium of communication and in fostering attitudes ... The evidence seems fairly clear that television does not stimulate interest or broaden horizons to any greater degree than would happen in its absence ... Several studies show that the heavy use of escapist material is associated with tendencies to anxiety, social maladjustment and frustration ... There appears to be no evidence that television makes children passive and there is little to make us believe that violent programmes on television reduce the likelihood of violence in real life ... On the whole the weight of evidence is behind the conclusion that the heavy dosage of violence in the mass media, while not a major determinant of crime or delinquency, heightens the probability that someone in the audience will act aggressively in a later situation.

From Nature 2 January 1965

\section{Years Ago}

Plague and Pestilence in Literature and Art. By Dr. Raymond Crawford - Dr. Crawford has treated his subject as much in its mental and moral aspects as in its physical, and the result is a wise and very interesting book... From century to century ... theories of its causation are rife. It is the work of malignant demons; it is sent from heaven in punishment for sin; it is the result of evil magic exercised by man on man; it is engendered in the clouds ... The contagious character of the disease was recognised by lay observers long before it was accepted by science ... Science does move, moreover, even though it be but slowly, slowly.

From Nature 31 December 1914

\title{
Diverted on the way to memory
}

\section{The finding that protein A of Staphylococcus aureus diverts the immune response so that it ineffectively responds to other structures from the bacterium explains the failure of ongoing attempts to develop working $S$. aureus vaccines.}

\section{GORDON Y. C. CHEUNG \& MICHAEL OTTO}

$S$ taphylococcus aureus is a global pathogen of great importance, causing thousands of deaths each year in the United States alone. The main problems with $S$. aureus infections are frequent resistance to antibiotics and the large repertoire of molecules produced by the pathogen to subvert human immune defences ${ }^{1,2}$. Notably, there is no protective immunity towards $S$. aureus, meaning that previous $S$. aureus infection does not defend an individual against subsequent infections. Writing in the Journal of Experimental Medicine, Pauli et al. ${ }^{3}$ describe a mechanism by which one $S$. aureus molecule, protein A, overwhelms the host's immune machinery through excessively stimulating certain immune responses while suppressing reactivity toward other key virulence determinants of the bacterium. These findings explain the weak protective immune responses and lack of immunological memory observed with S. aureus infections.

The human immune system has two ways to combat bacterial invaders. One is innate immunity, so-called because the response mechanisms involved do not require adaptation; rather, the immune cells recognize structures that are evolutionarily conserved among pathogens, resulting in the pathogens' quick elimination. S. aureus has a large repertoire of 'weapons' to subvert this aspect of human immune defence - such as toxins that the bacterium and the innate immune response determines whether an $S$. aureus invasion develops into a longer-lasting infection.

The other system is adaptive immunity, which mostly involves T cells and B cells. In B cells, adaptive immune responses lead to genetic rearrangements that result in differentiation into plasma cells, which produce antibodies that are specific to certain structures (antigens) and that trigger mechanisms to remove the pathogens expressing those structures. About $10 \%$ of plasma cells survive after an infection is cleared; these 'memory B cells' provide protective immunity against further infections with the same pathogen. Adaptive responses kick in about a week after the initial infection and normally provide long-lasting immunity.

In the case of $S$. aureus, the role of adaptive immunity is poorly understood, but it is clear that long-lasting protective memory is not generated. This is not only reflected by recurring $S$. aureus infections, but also by the fact kill white blood cells - and the battle between

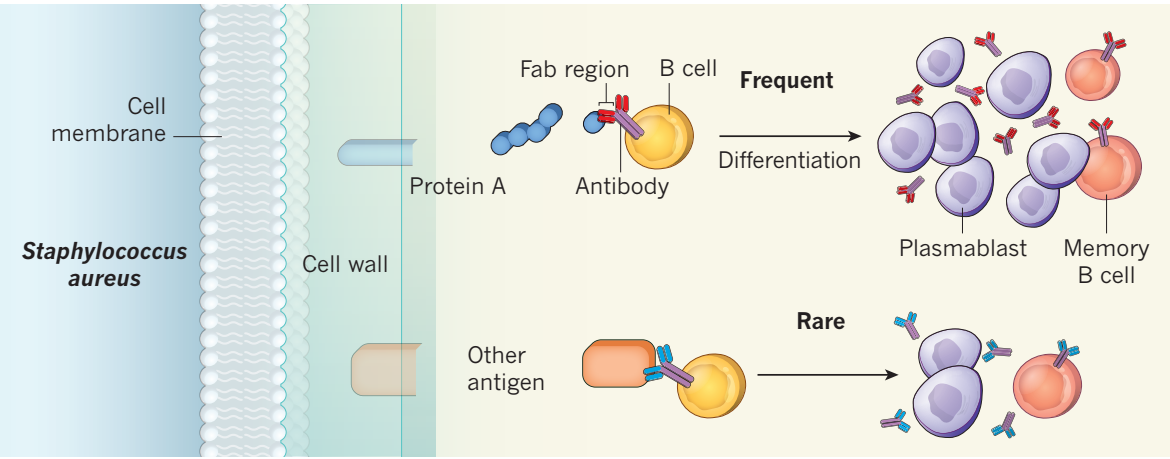

Figure 1 | Protein-A-dependent immune evasion. Protein A of Staphylococcus aureus contains a region of repetitive domains, part of which binds to the Fab region of antibodies in a nonspecific, 'superantigenic' manner. Pauli et al. ${ }^{3}$ propose that this superantigenic binding biases the B-cell immune response to S. aureus towards protein A. They observe that, of the B cells that differentiate to become antibodyproducing plasmablasts during an S. aureus infection, the majority bind to, and produce antibodies against, protein $\mathrm{A}$; very few $\mathrm{B}$ cells that bind to other $S$. aureus antigens undergo this differentiation process. This means that the memory B cells that remain after an infection, and that are 'primed' to mount immune responses to repeat infections, will also be mostly specific for protein $\mathrm{A}$. This may explain the lack of protective memory against $S$. aureus infections, because such protection requires immune activity against multiple virulence determinants of the bacterium. 